\title{
Uma perspectiva realista crítica sobre ação coletiva em economia
}

A critical realist perspective on collective action in economics

THIAGO DUARTE PIMENTEL RODRIGO SIQUEIRA RODRIGUEZ*

RESUMO: A visão predominante na economia tradicional assume que o objeto de análise das relações econômicas é o indivíduo, seja pela interação econômica entre eles (troca) seja pela interação econômica entre indivíduos e coisas (produção). Dificilmente a ciência econômica assume suposições a respeito de indivíduos organizados coletivamente. Em geral, quando o faz, assume que estas formas sejam um efeito agregado das ações individuais isoladas, ensejando assim uma posição baseada no individualismo metodológico. Em microeconomia, por exemplo, uma afirmação sobre um grupo de indivíduos, uma firma ou mesmo a sociedade, assume necessariamente que suas ações sejam abordadas a partir dos efeitos de maximizações individuais, ainda que isso exija a generalização de condições rígidas sobre o comportamento humano, improváveis para sustentar as crenças e os desejos individuais. Esse trabalho tem como objetivo apresentar um modelo de análise alternativo àquele paradigma, que simultaneamente esteja comprometido com uma análise realista e incorpore elementos contextuais e empíricos alusivos à conduta humana. Situando nosso foco no nível mesossociológico de análise, argumentamos que a análise da ação coletiva, fundamentada no realismo crítico, constitui-se numa alternativa para direcionar os estudos em economia.

PALAVRAS-CHAVE: Realismo crítico; ação individual; ação coletiva; organizações.

ABSTRACT: The mainstream of traditional economics assumes that the analyses of the economic relations is the individual, by the economic relationship among themselves (exchange) or by the economic relationship among individuals and things (production factors). Hardly the economical science takes assumptions about collectively organized individuals. In general, when it is done, it assumes that it is an effect of aggregate actions of isolated individuals, which means it lays on the grounds of methodological individualism. In microeconomics, for example, a statement about a group of individuals, a firm or a society, necessarily assumes that their actions are aggregate from the effects of individual

\footnotetext{
* Docente Permanente do Programa de Pós-Graduação em Ciências Sociais - Universidade Federal de Juiz de Fora - UFJF. E-mail: thiagodpimentel@gmail.com; Doutorando em Economia no Programa de Pós-Graduação em Economia da Universidade Federal Fluminense - PPGE/UFF: rodrigorodriguez@ id.uff.br. Submetido: 8/Julho/2015; Aprovado: 17/Novembro/2015.
} 
optimizations, even if this requires very strict conditions for the individual beliefs and desires. This paper aims to present an alternative analytical framework to that paradigm, simultaneously compromised with a realist analysis and incorporating empirical and contextual elements allusive to human conduct. Positioning our emphasis in the mesosociological level of analysis, we argue that the analysis of collective action, informed by critical realism, could be an alternative to drive the study of economics.

KEYWORDS: Critical realism; individual action; collective action; organization.

JEL Classification: B1; B41; B5.

\section{INTRODUÇÃO}

A visão predominante na economia tradicional assume que o objeto de análise das relações econômicas é o indivíduo, seja a relação entre os próprios indivíduos (troca), seja a relação entre indivíduos e coisas (produção). Dificilmente a ciência econômica assume suposições a respeito de indivíduos organizados coletivamente. Em geral, quando o faz, ela assume que estes sejam um efeito agregado das ações individuais isoladas, ensejando assim uma posição baseada no individualismo metodológico (IM). Em microeconomia, por exemplo, uma afirmação sobre um grupo de indivíduos, uma sociedade ou firma assume necessariamente que suas ações sejam abordadas a partir dos efeitos de maximizações individuais, ainda que isso exija a generalização de condições rígidas sobre o comportamento humano, e improváveis para sustentar as crenças e desejos individuais (Rosenberg, 1980).

Ainda que seja de grande interesse de outras áreas das ciências sociais, na ciência econômica a ação coletiva é geralmente negligenciada devido à prevalência do método individualista e sua compatibilidade com o conceito racional-maximizador, ambos pressupostos estruturantes desta ciência. Tais pressupostos impõem hipóteses rígidas para o comportamento individual, apresentando-se como uma restrição metodológica à produção de conhecimento em economia.

Essas suposições, que partem de uma estrutura teórico-metodológica positivista, podem ser entendidas de acordo com o que Popper (2011) chama de "estratagemas de imunização", sendo hipóteses que visam mais blindar as teorias de outras prescrições metodológicas e direcionamentos científicos do que prover um sustento teórico razoável capaz de explicar as relações que envolvem a economia, tanto do ponto de vista da produção como da troca. Essa visão comum em economia trata os fatos sobre as sociedades exclusivamente em termos de indivíduos, colocando a análise de instituições e grupos organizados em um papel secundário - estes últimos ainda de forma mais marginal.

Como o IM discute os fatos sobre as sociedades exclusivamente em termos de indivíduos (Bhaskar, 1998), na perspectiva do mainstream a análise de grupos organizados e instituições inevitavelmente emana um sentido distorcido e secundário, sendo o IM a base de um conjunto de afirmações que tem como finalidade autoimunizar a teoria econômica da natureza social das relações humanas, adquirindo, cada vez mais ao longo de sua tradição, um caráter subjetivo e abstrato, 
antirrealista. Afirmações comuns ao escopo neoclássico, como "o indivíduo busca o melhor para si”, "tomar a melhor decisão dentre as alternativas possíveis", "tomar a escolha que maximiza o seu retorno" são o reflexo dessa argumentação que vem sustentando argumentos na economia neoclássica baseados em silogismos e tautologias (Boland, 1992), supostamente tidos como enunciados lógicos e auto-evidentes, embora muito frágeis do ponto de vista científico.

A relevância do tipo de análise ora proposta torna-se mais clara a partir do momento em que se considera a pretensão teórica de analisar a sociedade a partir de uma ação cada vez mais externa e independente às ações específicas de um indivíduo ou da interação entre dois indivíduos. Propõe-se uma análise que conjuntamente não se negligencia o papel da ação individual nas relações sociais, assim como também não se atribui o fenômeno exclusivamente à estrutura social (uma visão antirracional).

Essa visão ponderada se torna viável uma vez que se assume o corpo teórico de discussão do realismo crítico (RC). O RC é um movimento científico embasado nos conhecimentos da filosofia e da sociologia que adquiriu notoriedade nos últimos anos, sendo uma via de crítica tanto ao realismo empírico (positivismo) presente na visão da ciência econômica, quanto ao idealismo transcendental (construtivismo) - sendo esta discussão o atual mainstream nas ciências sociais.

Além desta introdução, na segunda seção se discute o atual estado da ciência econômica tradicional, com ênfase em seus aspectos metodológicos. Aborda, em seguida, a crítica ao paradigma neoclássico e sua abordagem por diversos críticos teóricos, incluindo algumas propostas teóricas e metodológicas. Posteriormente, na quarta seção, apresenta-se uma síntese dos principais elementos do RC, e, na quinta seção, o modelo de interação esboçado como alternativa a esse problema, bem como se discute sua aplicabilidade em economia. Nas considerações finais, sexta e última seção, além de avaliar as potencialidades e limitações faz-se um arrazoado da proposta que enseja este artigo.

\section{O ESTADO DA ARTE (DO MAINSTREAM) EM ECONOMIA}

O senso predominante no mainstream da economia assume que o objeto de análise das relações econômicas é o indivíduo, a saber, a interação econômica entre os próprios indivíduos (troca), a interação econômica entre indivíduos e coisas (produção). Na microeconomia, cria-se um sistema fechado de condições perfeitas para a criação de problemas de interações entre tais relações de troca e produção, solucionadas pelo conceito de mercado, sendo sua máxima teórica o equilíbrio geral. Na macroeconomia, agregam-se os indivíduos de forma contábil: somam-se suas unidades, suas despesas, suas receitas, seu consumo, entre outras variáveis de interesse, em sua forma mais recente; "microfundamentada". Tal crítica tem sido desenvolvida, com finalidades distintas, no seio de vertentes heterodoxas, seja na tradição marxista ou pós-keynesiana (Arestis, 1992; Davidson, 2011), mas têm 
igualmente servido de base e sido substancialmente estruturada pelos precursores do RC, especialmente Tony Lawson (1997) e Roy Bhaskar (1998).

Diante de tais perspectivas que compreendem a forma como é estruturada a economia tradicional, o elemento metodológico capaz de permitir que as conexões e relações dentro desse modelo abstrato funcionem é o IM, conjuntamente ao princípio de racionalidade econômica (Rodriguez, 2015). O primeiro permite a formulação das condições simplificadas de um sistema fechado baseado em indivíduos, e o princípio da racionalidade precondiciona a ação do indivíduo para uma determinada posição previsível - ou conjunto muito restrito delas.

Essa estrutura é predominante na denominada economia neoclássica, mas pode ser encontrada em outros desdobramentos da mesma teoria, que abarcam o mesmo escopo teórico e método. Pode-se definir tal princípio como todas as interpretações que afirmam, independentemente da forma, que a ação humana é racional dadas as finalidades (ou preferências) e crenças (ou teorias) do agente no momento da ação. Sendo assim, o princípio de racionalidade diz respeito à consistência subjetiva "contextual" da ação humana, no sentido de que faz referência apenas a fins do agente ou preferências e crenças no momento da escolha e em local e quadro específicos de referência. Seja qual for a natureza de suas preferências ou crenças, suas ações são racionais enquanto apresentam consistência com suas preferências e crenças quaisquer que sejam no momento da escolha.

No entanto, as visões formalizadas através do princípio racional, em geral, são problemáticas por reduzirem toda complexidade decisória a um único elemento lógico que, ainda que frequente nas decisões humanas, não é um imperativo comportamental. ${ }^{1}$ Assim, no mundo real, além de as pessoas efetivamente não realizarem a "maximização" em suas decisões (Simon, 1955), sendo uma pressuposição falsa, negligencia-se todo e qualquer efeito das interações entre o indivíduo e a sociedade, sendo que em muitos casos e situações as decisões do indivíduo podem ser muito mais reflexo da estrutura social na qual está inserido, ou de decisões tomadas em suas redes (grupos e organizações as quais se envolve), indicando que sua decisão é também fruto das suas identidades com o ambiente social (Weber, 1978).

A definição clássica de IM é a doutrina na qual os fatos sobre as sociedades e fenômenos devem ser explicados exclusivamente em termos de fatos sobre indivíduos (Bhaskar, 1998). Em tal circunstância, as instituições exercem papel específico de "modelos abstratos" criados para interpretar fatos de experiências individuais.

\footnotetext{
1 Weber, por exemplo, em sua tipologia dos modos de ação social, considera além das formas de ação racional (seja com relação a fins seja com relação a valores) as formas de ação não racionais, como aquelas embasadas na tradição (ação social tradicional) ou motivadas pelo afeto (ação social afetiva). Estes dois últimos casos igualmente fundamentam formas de conduta humana que se materializam em relações de produção e/ou troca, haja vista, por exemplo, o caso de empresas familiares ou o consumo de serviços sexuais, drogas, busca por prestígio, etc. A própria análise marginal da utilidade do prazer - tema central do liberalismo - poderia ser fundamentalmente atribuída a esta rubrica, já que parte de suposições com relação à conduta humana (maximização do prazer) são essencialmente de ordem não racional (ou afetiva). Cf. Mill, John S. Utilitarismo. (1879[2015])17ª Ed. London: Longmans, Green \& Co.
} 


\section{CRÍTICAS À ECONOMIA POLÍTICA (NEO)CLÁSSICA}

Existem diversas vias de discussão em economia política do conceito de racionalidade neoclássica, sua peculiaridade individualista e também seu caráter meramente normativo, uma vez que é um conceito apreendido no espaço e no tempo. Sohn-Rethel (1978) defende a tese de que esse tipo de conduta racional está associado à necessidade da linguagem matemática, advinda de abstrações inerentes à própria mercadoria e ao processo de troca, através do argumento de que os fundamentos do modo racional de pensar se constituíram através de tal abstração tanto na Grécia Antiga quanto na ciência moderna.

Uma caracterização dos elementos da racionalidade neoclássica, como a instrumentalidade, formalidade, lógica e seu caráter dedutivo é apresentada por Searle $(2001)$. Augusto $(2011,2014)$ discute a estrutura da racionalidade neoclássica, abarcando tanto as limitações da racionalidade limitada apresentada por Herbert Simon, quanto às limitações da racionalidade estratégica de Von Newmann e Morgenstein, além de uma explicação ontológica para a normatividade presente no conceito de racionalidade através do conceito de eficiência (Rodriguez, 2015).

Lawson (1997) pondera que tal hipótese de racionalidade é fundamental para o modelo de explicação conhecido como dedutivista, onde há relação de causalidade do tipo "se X, então Y", mas que, entretanto, esse modelo só é usual em sistemas fechados, onde é pressuposto que existe previsibilidade das ações. Em oposição a este modelo ele oferece sua análise da atividade experimental, onde considera a economia - assim como as demais atividades humanas - operando em sistemas abertos, nos quais uma conjunção constante de eventos, de forma a gerar uma regularidade, seja ela sincrônica ou diacrônica (que é o que se passa nos sistemas fechados), é apenas uma possiblidade que se opera nos sistemas abertos.

Essas críticas, em síntese, podem ser sistematizadas em dois grandes argumentos: de um lado, a crítica ao IM, e de outro, a crítica ao instrumentalismo (formalismo) e irrealismo. No IM, a análise de grupos organizados e instituições apresenta um sentido distorcido e secundário, já que dificilmente pode ser objeto de análise simplista de agregação de preferências.

Uma implicação disso, por exemplo, é a interpretação equivocada de que o exército é uma mera "soma" de soldados, ou, em economia, de que uma indústria é a simples agregação de resultados de decisões individuais de trabalhadores (que decidem entre lazer e trabalho) e capitalistas (que decidem entre acumular ou consumir) (Bhaskar, 1998). Tal análise desconsidera - aquilo que é central na explicação realista crítica - os processos de emergência que ocorrem devido a um efeito de configuração específica de estruturas de um nível inferior, gerando, assim, um novo poder causal e a emergência de um novo tipo de estrutura de nível superior. Não por acaso, os modelos que são referenciados por tais princípios acabam por tomar posições fortemente restritivas com relação ao universo social, por meio de um empirismo manifestado sob suposições bastante severas e um instrumentalismo sob hipóteses irrealistas.

$\mathrm{O}$ instrumentalismo irrealista refere-se à abstenção de seu caráter explicativo 
com a finalidade de se adequar às suas presunções teóricas. Nessa literatura, Popper (2010), defende que o princípio da racionalidade dentro de seu modelo situacional é ausente de fundamento empírico e psicológico, uma vez que propõe que o esforço teórico do pesquisador deva se dar em direção à teoria explicativa e ao modelo, e não em relação a uma hipótese auxiliar, afirmando que dificilmente um modelo deixa de ser usual por conta de sua suposição sobre o comportamento humano.

De forma mais radical, Friedman (1953), em uma tentativa de reafirmação do que é ciência positiva em economia, argumenta que as suposições são irrelevantes para a validação das teorias e que as teorias devem ser julgadas quase que exclusivamente por seu valor instrumental de gerar previsões precisas. A crítica ao instrumentalismo se deve justamente à sua pretensão: não deseja explicar o que os seres humanos fazem, mas simplesmente como fazem, entretanto, com uma possibilidade de elucidação de episódios empíricos (Bhaskar, 1998).

Grande parte do esforço diante da crítica em propor alguma teoria ou metodologia específica para solucionar as deficiências da racionalidade se exerce sobre o sujeito da economia neoclássica, o indivíduo. Herbert Simon $(1955,1956)$ aponta que não se pode usar o cálculo maximizador, que em sua visão é válido no nível de mercado, como pressuposto econômico para a análise do comportamento humano no nível de agente econômico. Para Simon $(1955,1956)$, os economistas devem explicar o comportamento dos indivíduos no nível de mercado, partindo do entendimento do agente econômico, o que envolve entender, sob o ângulo da psicologia humana, a própria forma na qual os indivíduos interagem, sugerindo um princípio de aproximação realista.

As propostas que se apresentam como rupturas mais significativas com relação ao escopo neoclássico positivista dificilmente conseguem servir ao padrão de explicação e previsão da teoria neoclássica. ${ }^{2}$ Geralmente, ficam restritas a análises e discussões internas de teorias que dialogam pouco com os modelos tradicionais. A escola austríaca, por exemplo, em sua tentativa de imunização das teorias à crítica, rejeita o teste de suas formulações, afirmando suas suposições como verdadeiras a priori, e assim segue em sua interpretação do sujeito racional, como uma verdade preestabelecida e óbvia (Caldwell, 1994).

\section{ALGUMAS CARACTERÍSTICAS CENTRAIS DO REALISMO CRÍTICO}

Analisar a ação coletiva também deve tomar os seus cuidados e ser conduzida pelos elementos teóricos do RC. Negar o paradigma racional maximizador neoclássico e apresentar um modelo que dialoga também com as estruturas macrosso-

\footnotetext{
${ }^{2} \mathrm{O}$ marxismo e sua proposta sociológica relacional por bases ontológicas é um exemplo de resposta ao individualismo metodológico, se apresentando como uma visão mais ampla. Apesar disso, existem severas diferenças entre o marxismo e o realismo crítico, tendo autores como Prado (2009) e Gunn (1989) que medem esforços na diferenciação em favor do marxismo. Do ponto de vista realista crítico, Brown, Fleetwood e Roberts (2002) estabelecem críticas que se separam do marxismo.
} 
ciológicas pode conduzir a uma visão demasiadamente antiessencialista, construtivista. Muitos autores da vertente defendem que o RC assume uma posição intermediária entre os extremos dessa relação, como discutido por Alsted (2011).

Figura 1: Continuum de posições epistemológicas acerca da essencialidade da realidade

Realidade

Realidade

Independente

dependente de nós

Essencialismo Positivismo Estruturalismo Realismo Crítico Construtivismo Social Construcionismo Radical

Fonte: Alsted (2011).

O RC trabalha com duas teses principais: (1) a reivindicação da ontologia e sua irredutibilidade à epistemologia; e (2) a estratificação desta ontologia, a partir de mecanismos generativos ativos, dos eventos e dos fatos observáveis, que podem se manifestar ou não (Vandenberghe, 2007; Pimentel, 2014, 2015).

O RC reivindica como posição a ontologia realista, em que a realidade é vista como algo ou entidade externa e independente do ser humano ou do conhecimento que ele possa ter ou vir a ter da realidade. Segundo Bhaskar (1989), este domínio ontológico - ou dimensão intransitiva - é constituído de diferentes estratos ou níveis, aos quais se pode (ou não) ter acesso e gerar conhecimento: o empírico, que é o mais superficial estrato da realidade e constitui-se das manifestações empíricas de um dado fenômeno, e que, portanto, podem ser observadas; o estrato efetivo, não necessariamente observado, referente aos eventos ou a ocorrência de sucessivas transformações na realidade; e o estrato do real, o mais profundo nível da realidade, que remeteria às propriedades internas e intrínsecas de cada entidade (coisa em si) e que seria responsável por desencadear a atuação das manifestações de um fenômeno, nos demais níveis, já que aqui neste nível é que residiriam, de forma imanente, os poderes causais das entidades, sendo ativados mediante a sua exposição a determinadas circunstâncias (Jessop, 2005; Vandenberghe, 2007).

Contrariamente à visão superficial e acrítica da realidade (empirismo), os realistas críticos apontam que é possível identificar pelo menos quatro formas de realidade: (1) a material, que se refere a entidades materiais como a água ou a terra, que existem independentemente do que os indivíduos ou comunidades façam, digam ou pensem; (2) a ideal, que se refere a entidades conceituais tais como discurso, gênero, símbolos etc. que podem ser entendidas como entidades discursivas, e que têm eficácia causal e que podem ter (ou não) um referente que pode (ou não) ser idealmente real; (3) a artefactual, referindo-se a entidades - tais como cosméticos ou computadores - que são uma síntese de entidades física-ideal-socialmente reais; e (4) a social, que se refere a práticas, estados de coisas, estruturas sociais que constituem organizações humanas (Fleetwood, 2005).

Um segundo elemento do RC é a dimensão transitiva do conhecimento - ou epistemológica - que, em vez de orientar o processo de descoberta científica, passa a ser orientada pela dimensão intransitiva ou ontológica. Para Bhaskar (1989) uma das características mais significantes das ciências sociais é que o fenômeno 
social ocorre somente em sistemas abertos, enquanto na esfera natural há a possibilidade de fechamento artificial desses sistemas, como observado na física ou na química, e de fechamento parcial, gerando sistemas quase fechados na biologia, mas com alto grau de controle das variáveis. Daí segue-se que situações decisivas de teste são impossíveis. Então, o critério de escolha de uma teoria ou desenvolvimento teórico deve ser exclusivamente explicativo e não preditivo ${ }^{3}$.

Jessop (2005) coloca que o conhecimento - domínio transitivo - é feito através de um processo contínuo de confrontação entre hipóteses teóricas retrodutivas sobre os objetos intransitivos e demonstrações evidentes (ou evidenciáveis), geradas através da investigação transitiva. Estas demonstrações são mediadas pelo resultado da investigação científica e nunca refletem diretamente o domínio real ou o fenômeno atual (domínio efetivo).

O problema, então, de como resolver qualquer inconsistência entre hipóteses e evidência seria determinado dentro do paradigma prevalecente (hegemônico), com suas regras da ciência. Mas para estas regras serem aceitas como científicas elas devem prover uma base para julgamento racional entre diferentes reivindicações. Estas regras pertencem ao aspecto transitivo da ciência e por isso estão sujeitas a revisão e desenvolvimento.

Assim, chega-se a um terceiro elemento central do RC: o processo de racionalização científica (rationale). No RC, a busca pela racionalização e explicação científica percorre um caminho diferente da visão convencional. Com questões como: "como o mundo/realidade tem que ser para que ele seja passível de conhecimento por nós?"; e "que propriedades possuem as sociedades que podem torná-las possíveis objetos de conhecimento para nós?” (Bhaskar, 1998, p. 1) Bhaskar inverte a tradicional lógica de questionamento, passando da ênfase na agência (como eu conheço o mundo?) para a ênfase no objeto ou coisa em si (como ele é ou deve ser para que possa ser conhecido?) e com isso muda o sentido e a orientação do raciocínio filosófico e científico - no realismo transcendental - gerando o que ele chama de retrodução ${ }^{4}$.

De acordo com Bhaskar (1998, p. 20-22) as “[...] simples generalizações empíricas somente são aceitáveis na ausência de conhecimento sobre os poderes causais ou mecanismos e outras condições que formam a melhor base para a retrodu-

\footnotetext{
${ }^{3}$ Como consequência, existem duas posições extremas sobre sistemas abertos: uma seria a possibilidade de se negar qualquer controle a numa teoria independentemente de sua aplicação prática, o que ressaltaria o caráter de impossibilidade de teste preditivo. A outra seria a observação do uso de uma bateria de técnicas estatísticas como mais ou menos adequada para se tentar substituir o fechamento experimental, o que negligenciaria os limites qualitativos da medição e a probabilidade de variação dos sistemas abertos.

${ }^{4}$ A retrodução é um tipo de raciocínio lógico-filosófico (passível de ser transposto para campo científico) que embasa o pensamento crítico-realista. Ela formula um questionamento que visa reconstituir a trajetória de formação de uma entidade a partir de seu estágio atual, em direção ao passado. Por exemplo: Como teria que ser X para que se tornem objetos de conhecimento para nós? Que propriedades teriam o objeto $X$ para que ele se tornasse objeto de conhecimento para nós (fosse possivel ser conhecido)?” (Jessop, 2005: 43 - itálicos no original, tradução livre).
} 
ção descobrir os mecanismos e obter as condições que os geram". Isto é ilustrado pelo registro de Lawson (1997) na economia, quando ele aponta a presença de semi-regularidades ocorridas num espaço físico. A identificação destas certas regularidades é facilitada por meio da comparação, o estudo de crises econômicas, e as análises contrafactuais. Geralmente, a explicação adequada é somente relativa a um dado explanandum. Isto pode mover-se do abstrato para o concreto, isto é, pelo aumento gradativo da materialização de um dado fenômeno e do simples para o complexo. Ou, em outras palavras, pela introdução de novas dimensões de um dado fenômeno (Jessop, 2005). Dessa forma, reconhece-se que nenhuma explicação é sempre e totalmente completa. Ela pode ser sempre (re)definida ou questionada fazendo-se o explanandum mais concreto e/ou complexo.

\section{O MODELO}

Partindo da perspectiva crítico-realista desenvolvida de forma particular para aquilo que Friedberg (1993) chama de sociologia da ação coletiva organizada, Pimentel (2012) elabora um modelo que assume a existência de três grandes níveis de análise importantes entre si, que comumente na sociologia se apresentam pelos níveis micro, meso e macro. Essa divisão, retomada de Vandenberghe (2010), reconhece os níveis da seguinte forma: (1) nível microssocial, (2) nível mesossocial e (3) nível macrossocial; os quais, por sua vez, podem ter subdivisões em ordens.

No primeiro nível, microssocial, faz-se referência às análises sociais nas quais o foco é a observação da ação humana em detalhe, em recortes e fragmentos espaçotemporais pontuais. Esse nível se subdivide em duas ordens (subníveis), que são: a) a ordem individual - corresponde aos fenômenos e entidades responsáveis pela atividade humana individual; e b) a ordem interacional - que aborda as interações entre dois ou mais indivíduos, também num contexto pontual. Se assemelha à análise comumente abordada na análise econômica tradicional, tanto na microeconomia como na macroeconomia.

O nível mesossocial, por sua vez, diz respeito à análise da dinâmica grupal, isto é, das interações entre vários indivíduos numa escala da realidade local em que ainda ocorre interação face a face, embora esta possa estar sendo complementada ou gradativamente substituída por interações mediadas. Este nível incorpora análises que versam sobre os fenômenos organizacionais e institucionais, e, em geral, fazem referência à emergência de algum tipo de ordem social.

Já o nível macrossocial refere-se às estruturas sociais amplamente institucionalizadas e normativas, que se sobrepõem aos comportamentos dos indivíduos e grupos. Se divide em: a) ordem cultural, que engloba os fenômenos relativos às produções culturais humanas, materializadas ou não; e b) ordem social, que agrupa a existência de entidades e estruturas altamente estáveis e mais sedimentadas.

Identificados esses níveis, o modelo proposto centra sua análise na classe de fenômenos que ocorre no nível mesossocial. O modelo se inicia com a delimitação de um campo, real ou potencial, de atividade social. Para isso, utiliza-se a 
definição de campo de Bachelard (2010), amplamente disseminada e utilizada pela sociologia francesa pós-1950, em sua forma mais amplamente elaborada por Pierre Bourdieu (1983). Essa noção de campo tem função distintiva, em um processo de diferenciação e de di-visão (Bourdieu, 1983), e será empregada com o intuito de delimitar o raio da visão e atuação coletiva (Bourdieu e Wacquant, 2005; Pimentel, 2012).

Identificado o campo, procura-se identificar qual "jogo" se desenrola neste campo. O jogo é uma especificação operativa do campo, isto é, a forma como o campo funciona, por meio da particularização de uma situação real, em que é possível identificar os jogadores reais, as regras, os objetos do jogo, bem como os adversários. Tanto o campo quanto o jogo recorrem, de imediato, como elemento mais básico para o seu acontecimento, a um espaço físico (e social) localizado na realidade, e remete à relevância da dimensão espacial, portanto, a dimensão espacial é a dimensão onde os constrangimentos estruturais são inicialmente formadas e se tornam empiricamente materializados (Pimentel, 2012).

Assim, o Modelo de Estruturação dos Sistemas Sociais de Ação Coletiva, elaborado por Pimentel (2012), inspirado em uma perspectiva morfogenética, pode ser sintetizado em três momentos:

1) M1 - Espacialização, dada pela situação de copresença, física ou virtual, que permite o compartilhamento de uma mesma situação ou contexto da realidade material, que traz constrangimentos e habilitações (num primeiro sentido físicos, mas não apenas dessa forma) aos componentes (indivíduos) sujeitos enqua${\underline{\operatorname{drados}^{5}}}^{5}$ nesta situação (Elder-Vass, 2010; Lacoste, 2008; Fleetwood, 2005);

2) M2 - Identificação, que diz respeito ao compartilhamento de uma realidade ideal, na forma de símbolos comuns que unificam os indivíduos em interação, e permite a formação de uma comunidade imaginada, que irá estabelecer os limites do grupo social, bem como as bases ideais e afetivas, os valores e os sentimentos de afiliação e pertencimento do indivíduo ao grupo social (Vandenberghe, 2010; Elder-Vass, 2010);

3) M3 - Representação, que diz respeito a um duplo aspecto de relacionamento do grupo, em face do seu ambiente interno (através de formas de representação de uma coletividade por um indivíduo ou grupo menor e de delegação de poderes a esses representantes) e externo (através de aquisição, por parte dos representantes da coletividade, de uma capacidade de expressão política no cenário externo à coletividade). Internamente, com a crescente diferenciação e complexificação do grupo social, há uma estratificação de funções internas que precisa ser coordenada para que seja possível a manutenção sem ruptura, ou seja, como uma estrutural social única. Em síntese, representa-se externamente os resultados dos conflitos

\footnotetext{
${ }^{5}$ A noção de enquadramento é importante porque estabelece, necessariamente, a delimitação (interna e externa) de um espaço e a inscrição dos atores neste espaço (físico e social), resultado do estabelecimento de um campo de forças.
} 
internos, com uma identidade singular, mediada por um representante (Luhmann, 1997; Fleetwood, 2008; Vandenberghe, 2010).

Para auxiliar a sintetizar o argumento dos três momentos, Pimentel (2012) elabora um esquema sobre o processo de estruturação da ação coletiva em sistemas sociais, considerando ainda a separação dos níveis da realidade social (figura 2).

O primeiro momento (M1), portanto, é a estrutura espaço-temporal que limita o campo de possibilidades do ambiente. $\mathrm{O}$ espaço (físico) pode ser visto como uma estrutura gerativa que tem a capacidade de fixar, isolar e circunscrever as demais entidades, limitando-as às condições, restrições e habilitações possibilitadas pelo ambiente físico no qual elas estão inseridas. Esse poder causal é ativado pela realidade material das entidades (estruturas). Como todas as entidades, as estruturas sociais estão fixadas ao espaço e são influenciadas pelas restrições físicas e simbólicas que este lhes impõe. Dado que todas as entidades estão fixadas a algum espaço, para que haja interação entre eles, elas precisam estar em uma situação de copresença física ou virtual.

De tal situação de copresença é que se estabelece a base para a interação das entidades. No caso das estruturas sociais, é na copresença que se deve localizar os constrangimentos que impõem as estruturas sociais em si, bem como as relações entre elas, que culminarão em determinado padrão de interação inicial e a possibilidade de geração de uma nova estrutura, dependendo da forma como interagirem.

No segundo momento (M2), uma vez formados pela situação de compartilhamento espacial, os grupos de interação estabelecem a base para a formação e a consolidação de uma estrutura social mais densa ou coesa. A densidade se dá aqui sobretudo pela intensidade de relações estabelecidas entre os componentes (indivíduos) do grupo (ainda pré-estruturado). Como subproduto desse grupo de interação com sua identidade própria, a coletividade social produzirá fronteiras sociais e físicas cuja função é demarcar claramente os limites da identidade do grupo e dos seus membros, evidenciando, assim, quem pode fazer parte do mesmo e quem não pode e, consequentemente, quem tem acesso aos benefícios ou é desprovido deles, bem como as sanções que se impõem aos membros e não membros; aqueles por desrespeitarem alguma norma e estes por não terem acesso aos benefícios.

Assim, o poder causal intrínseco que emerge dos grupos de interação pode ser observado como a capacidade de identificação e criação de um quadro de referência simbólica comum entre seus componentes, formando e/ou fortalecendo a formação de coerência interna e definição externa, resultando numa identidade.

O terceiro momento (M3) se manifesta predominantemente na forma da realidade social. Só existe a partir dos sujeitos sociais coletivos, que possuem a capacidade de exercer coerção. A dotação de coesão na identidade interna e o grau de complexidade das interações implica a delegação de funções por um representante da coletividade, um líder, por exemplo. Assim, o produto dessa tendência de autoestruturação e organização desse sistema de ação coletiva é a formação daquilo que, tradicionalmente, é reconhecido pela literatura como "organização formal”, altamente 


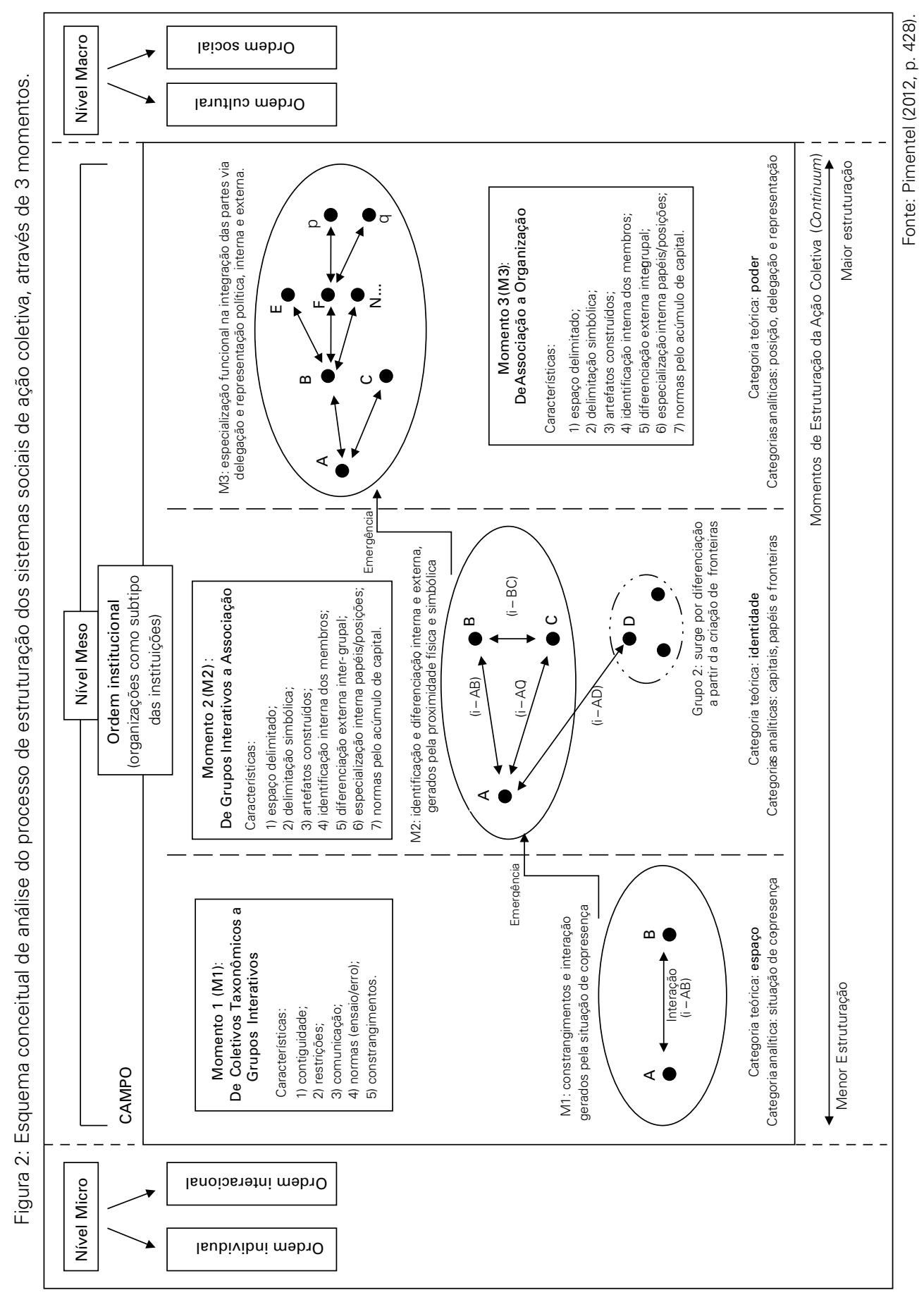


estruturada por relações características de terceira ordem (relações de relações de relações).

Dessa organização estruturada se emerge o poder causal da manifestação pública na área social, a capacidade de expressão política, a atuação e intervenção social em escala. Assim, exerce sob as demais estruturas sociais e nas instituições sua capacidade de moldá-las, uma vez que possui recursos e legitimidade, dentre as demais estruturas sociais. De tal forma, a organização aparece como "personagem coletivo" (Vandenberghe, 2010) com propriedade de exercer poder, reproduzir e transformar a realidade.

\section{O MODELO E SUA PLAUSIBILIDADE EM ECONOMIA}

A discussão do modelo em economia perpassa pela mudança no objeto de análise da ação individual para a ação coletiva (mais objetivada e independente das ações específicas de um indivíduo). Na metodologia positivista em economia, até mesmo o resultado autoevidente da ação coletiva é tratado como agente individual.

A primeira etapa de aplicabilidade do modelo é delimitar o caráter espaço-identidade de qualquer um desses complexos coletivos, e isso envolve em um primeiro momento compreender o nível de comunicação, constrangimentos e interações gerados pela situação de copresença entre os indivíduos (uma dimensão espaçotemporal) até o momento em que tais formas interativas, semiautônomas, de grupos evoluem para uma comunidade simbólica. Esta associação se identifica internamente e se diferencia externamente, delimitando-se espacialmente e simbolicamente. Uma das formas de compreender essa etapa é através da formação (e não formação) de conjuntos de redes entre os indivíduos, sendo as redes diferenciáveis entre si externamente e identificáveis entre si internamente.

Tais redes, ainda que possuam determinados aspectos da modernidade que as tornem menos localizadas e mais intangíveis, são ainda uma forma de copresença. O mais importante nesse momento para o economista é compreender o quão relevante a dimensão espacial é para o objetivo da pesquisa. Em termos analíticos, pode-se atribuir as características do ambiente do indivíduo que favorecem ou desfavorecem ele a entrar em uma situação de copresença física com outro indivíduo. A saber, tais categorias podem ser desde zonas geográficas (urbanas ou rurais, desenvolvidos, não desenvolvidos etc.), o que conduz às temáticas discutidas em teorias da localização e economia espacial, mas indo além, outras fronteiras espaciais entre os indivíduos, como suas rendas, níveis educacionais, classes sociais, além das barreiras culturais (castas, religiões, tradições etc.), raciais e de gênero, que se aproximam do conceito de campo de Bourdieu e que podem ser ponderadas pelo objetivo da análise. Em termos mais genéricos, podemos afirmar que existem forças reais (sejam em sua forma de manifestação material, ideal, social 
ou artefactual) que favorecem ou impelem a interação entre indivíduos, formando o campo de possibilidades das suas redes sociais.

A segunda etapa consiste na análise dos processos de identificação e construção identitária da coletividade em si, o que implica um novo grau de estruturação de ação coletiva. Análise esta que ocorre em dois níveis: interna e externamente. No primeiro, através da especialização funcional na integração das partes via delegação e representação política interna e externa, o que sugere a transição de uma associação simples para uma organização estruturada, com regras e normas implícitas. A compreensão das funções de cada indivíduo em meio ao seu coletivo, seus constrangimentos e suas atribuições devem ser relevadas nesse ponto. Tais grupos, a partir do momento em que seus indivíduos tomam decisões comuns, se identificam, reproduzem e transformam suas decisões de acordo com seu grupo, como se a organização tomasse um corpo próprio de regras tácitas aos seus membros, seja de condutas, ações ou até mesmo desejos. Institucionaliza-se um conjunto de símbolos que refletem efeitos sob os indivíduos, observáveis e não observáveis.

$\mathrm{Na}$ terceira etapa, a categoria "poder" permite compreender a estruturação progressiva da organização, a reprodução da organização estruturada que alcança proporções capazes até mesmo de instaurar uma ordem e intervir deliberadamente na realidade social, ou com os conflitos, a sua transformação. Essa categoria, caracterizada pela coerção, pode ser refletida nas relações entre grandes organizações como sindicatos e empresas, associações e Estado, capitais e Estado. Cada organização estruturada tem como imperativo reproduzir suas atividades através do representante delegado, e conflitos internos e externos poderão levar à transformação da própria organização, assim como também a possibilidades de alterar a realidade social (ou mantê-la).

Esse sistema social de ação coletiva pode ser analisado por meio da abordagem morfogenética e morfostática desenvolvida por Archer (1998) e, portanto, conforme as premissas estabelecidas pela perspectiva filosófica da ciência orientada pelo RC. Archer (1998) desenvolve seu modelo de análise ressaltando a convergência de sua proposta com o modelo elaborado por Bhaskar ${ }^{6}$. Contudo, a autora, ao retrabalhar o modelo funcionalista desenvolvido por Buckley (1967) dentro das premissas do RC e, portanto, buscando valorizar a possibilidade de mudança, confere maior destaque à análise morfogenética. Esse modelo pode ser demonstrado através do esquema da Figura 3 (Pimentel, 2012, p. 425).

\footnotetext{
${ }^{6}$ Bhaskar introduz o modelo transformacional de atividade social diferindo em termos ontológicos sociedade e pessoa, rejeitando as três posições "centrais": atomismo social e individualismo metodológico; reificação social e coletivismo metodológico e a visão comprometida de que indivíduos criam a sociedade e sociedade produz indivíduos em processo dialético contínuo (Archer et al., 1998, p. 212-213).
} 
Figura 3: Acréscimo dos elementos do modelo de análise morfogenética/morfoestática das organizações a partir da sobreposição do MTAS (Bhaskar) e de CMM (Archer)

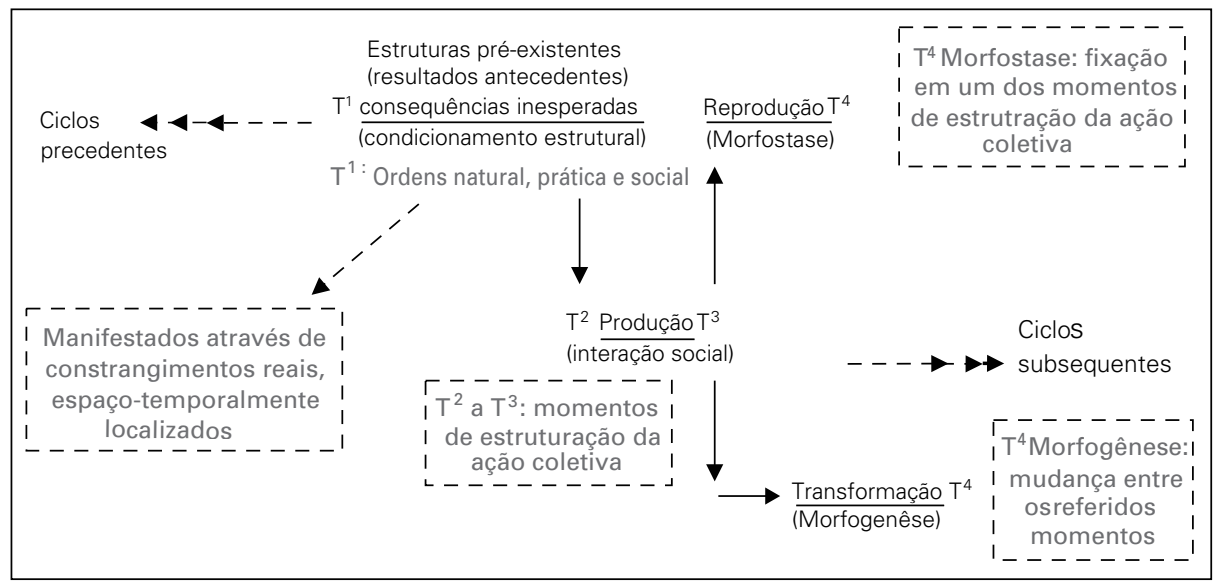

Fonte: Pimentel (2012, p. 428) adaptando elementos do modelo de análise morfogenética / morfoestática de Archer (1998, p. 376).

Uma ilustração do modelo, de forma simplificada, pode ser conduzida a partir dos conceitos chave apresentados. Tomando como exemplo a relação entre trabalho e capital, o modelo simples (sem estado e organizações da sociedade civil com poder de coerção nessa relação) pode ser construído da seguinte forma ${ }^{7}$ :

1) Identificação do campo: tema sobre o qual os agentes estão de acordo e que motiva suas interações.

2) Identificação do Momento 1 (M1) - Espaço, e seus elementos: situação de copresença e constrangimentos. Isso se materializaria, por exemplo com a análise do ambiente capitalista de produção e troca (para estudos empíricos, a delimitação espacial pode ser ainda mais específica, como no Brasil, na periferia etc.)

3) Identificação do Momento 2 (M2) - Identidade e seus elementos: formação de uma representação simbólica compartilhada, fronteiras simbólicas, coesão interna e diferenciação externa. Aqui, os coletivos sociais estruturados podem ser vistos em termos de capitalistas e trabalhadores, dois grupos que se diferenciam e estabelecem fronteiras entre si; fronteiras sociais, políticas, espaciais.

4) Identificação do Momento 3 (M3) - Poder e seus elementos: maior abrangência, complexificação, divisão do trabalho, especialização funcio-

\footnotetext{
${ }^{7}$ Outro exemplo factível é o problema de agência da firma. As afirmativas forçosamente "auto-evidentes" sobre gestores que "maximizam utilidade" e acionistas que "maximizam lucros" podem ser entendidas no contexto de um conflito que não envolve basicamente seus objetivos, mas sim diferenças de coletivos. Além disso, como organização o seu representante (o presidente) é a delegação interna dos acionistas que são externos à organização, além dos elementos de coerção advindos da sua posição.
} 
nal e formalização coletivos sociais estruturados; emergência da gerência, delegação interna e representação externa. Aqui cada agente - trabalhadores via sindicato, capitalistas via gerência - busca aumentar seu poder causal de intervenção na realidade através do exercício do poder, canalizado e organizado, pelos sistemas sociais de ação coletiva.

4.1) Os trabalhadores: cuja representação e expressão se faz pelo sindicato, utilizam-se de coerção para reivindicarem (interna e externamente) por maiores salários, menores jornadas de trabalho e melhores qualidades de trabalbo.

4.2) Os capitalistas: cuja representação e expressão se faz pela gerência de uma organização econômica formal, utilizam-se de coerção para buscarem (interna e externamente) maiores retornos financeiros.

5) Problema comum e dinâmica interativa (jogo): interesses conflitantes entre capitalistas e trabalhadores com relação a salário, jornada e condições de trabalho.

A interação social entre essas duas organizações pode conduzir, com base em suas ações coletivas para cada período, a manutenção ou transformação das relações existentes dinâmicas, não só sobre o conflito externo, mas também a modificação das próprias organizações, uma vez que o conflito interno é tão presente quanto o externo.

De acordo com a lógica positivista neoclássica, capitalistas e trabalhadores buscariam o melhor para si, de forma racional e maximizadora (salários e lucro, em simplificação). A questão central é que, mesmo numa perspectiva econômica tradicional, racional-maximizadora, buscar o melhor para si, em níveis mais amplos de ação, exige estruturação da ação social. A ausência deste tipo de problematização e debate nos leva a suposições irracionais empiricamente frágeis acerca do comportamento dos indivíduos e, por extensão, à mistificação e naturalização de modelos explicativos de credibilidade duvidosa e sustentação precária, impelindo todos, do perito ao leigo, a uma aceitação tácita de uma ilusão coletiva.

\section{CONSIDERAÇÕES FINAIS}

Como primeiro passo na construção de uma proposta teórica, o trabalho aponta sugestões e direcionamentos analíticos mais genéricos, mediante sua amplitude e possibilidades. A economia possui hoje uma variedade de instrumentos sofisticados (às vezes não adequadamente utilizados) que podem ser refinados a partir de uma noção de ação coletiva que envolva o papel da decisão individual do sujeito, mas que acrescente, discuta ou incorpore os efeitos dos fenômenos sociais sobre o indivíduo aos diferentes níveis meso e macrossociológicos, a partir do direcionamento sob três categorias: espaço, identidade e poder.

A categoria poder, em especial, merece atenção ainda maior dos economistas da linhagem heterodoxa. A emergência da análise institucional em economia, ainda que consiga assumir no modelo positivista uma série de refinamentos teóricos, ignora os efeitos de tendência das forças sociais sob as instituições e indivíduos inseridos em tais 
relações. As estruturas de mercado coercitivas (monopólio, oligopólio) também devem ser reinterpretadas em um ponto de vista de ação estruturada com coerção social.

Quanto ao fundamento econômico da interpretação desse modelo relacional, a troca, elemento mais básico de relação da economia, só ocorre porque, no mínimo, existem as condições espaciais e de identidade entre os indivíduos em um coletivo, e sem dúvidas coerção. Do ponto de vista introspectivo mais sugestivo, a troca só ocorre se ambas as partes reconhecem o caráter privado de seus bens e dos bens do outro, sendo essa capacidade muito mais atribuída aos efeitos das forças sociais que exercem sobre as partes do que sobre suas formas de decisão, ainda que exista um fator individual, que seja um cálculo mental. Excetuando-se a situação econômica controlada de sobrevivência em uma ilha de Robinson Crusoé, onde só há uma pessoa (caso este que tampouco seria caracterizado como uma ação social, quiçá econômica), existem diversos casos passíveis de análise em economia na qual a ação coletiva pode ganhar espaço.

Assim, considerando essa especificidade do modelo proposto, cabe ressaltar algumas limitações já identificadas nesta proposta. Esse modelo centraliza-se na análise da ação coletiva. Embora suas categorias centrais sejam referentes ao domínio ôntico e, portanto, intransitivas, segundo os objetos e os tipos de realidade, a lógica de inter-relação esboçada entre elas, no geral, e entre os conceitos internos de cada categoria, em particular, é supostamente adequada para os tipos de interação e emergência da realidade humana no nível mesossocial e nas suas respectivas escalas espacial e temporal.

\section{REFERÊNCIAS BIBLIOGRÁFICAS}

Alsted, Jacob. (2001) "Models of human motivation in sociology". Paper presented in the conference IACR Debating Realism(s), $5^{\circ}$ edição.

Archer, Margaret S. (1998) Critical Realism: Essential Readings. London: Routledge.

Archer, Margaret. (2002) "Realism and the problem of agency". Alethia, 5(1): 11-20.

Arestis, Philip. (1992) The Post-Keynesian approach to economics. Brookfield: Edward Elgar.

Augusto, André G. (2011) “Os limites da racionalidade limitada: Evidência empírica e escolha teórica”. In Anais do XVI Encontro Nacional de Economia Política.

Augusto, André G. (2014) “Uma sugestão de explicação ontológica para o caráter normativo da racionalidade neoclássica”. Revista da Sociedade Brasileira de Economia Política, 39:10-31.

Bachelard, Gaston. (2010) A experiência do espaço na física contemporânea. Rio de Janeiro: Contraponto. Bhaskar, Roy. (1989) Reclaiming Reality: a critical introduction to contemporary philosophy. London/ New York: Verso.

Bhaskar, Roy (1998) “Societies”. In Archer, Margaret; Bhaskar, Roy; Collier, Andrew; Lawson, Tony; Norrie, Alan (Ed.) Critical Realism: Essential Readings. London: Routledge, 206-257.

Bhaskar, Roy (1993) Dialetics: the pulse of the freedom. London: Routledge.

Boland, Lawrence A. (1992) The principles of Economics - Some lies my teachers told me. London: Routledge.

Bourdieu, Pierre (1983). “Algumas propriedades sobre os campos”. In: Ortiz, Renato “Questões de sociologia”. Rio de Janeiro (RJ): Marco Zero, 89-94.

Bourdieu, Pierre (1998). "O Poder Simbólico" Rio de Janeiro: Bertrand.

Bourdieu, Pierre; Wacquant, Loïc. (2005) Um convite à sociologia reflexiva. Rio de Janeiro: Nova Fronteira. Brown, Andrew; Fleetwood, Steve; Roberts, Michael, eds. (2002) Critical realism and Marxism. Londres/ New York: Routledge. 
Buckley, Walter. (1967) Sociology and Modern Systems Theory. Oxford: Prentice-Hall.

Caldwell, Bruce (1994) Beyond Positivism: economic methodology in the twentieth century. Londres: Routledge.

Davidson, Paul. Ed. (2011). Post Keynesian macroeconomic theory. New York: Edward Elgar.

Elder-Vass, Dave (2010). The causal power of social structures: emergence, structure and agency. Cambridge: Cambridge University Press.

Fleetwood, Steve. (2005) "Ontology in organization and management studies: a critical realist perspective”. Organization, 12(2).

Fleetwood, Steve (2008) "The ontology of things, properties and powers". Journal of Critical Realism, $8(3):$ p.343-366.

Friedberg, Erthard (1993) Le Pouvoir et la Règle. Paris: Editions du Seuil.

Friedman, Milton (1953) Essays in Positive Economics. Chicago: University of Chicago Press.

Gunn, Richard (1992) “Against historical materialism: Marxism as first-order discourse”. In W. Bonefeld, R. Gunn e K. Psychopedis, eds. Open Marxism - theory and practice. Londres: Pluto Press.

Hausman, Daniel M. (1981) “John Stuart Mill's Philosophy of Economics”. Philosophy of Science, Chicago, 48(3): 363-385.

Jessop, Bob (2005) "Critical realism and the strategic-relational approach. New Formations, 56(s/n): 4053. Disponível em: <http://www.lwbooks.co.uk/journals/newformations/articles/56\%20jessop.pdf>. Acesso: 15 jan. 2012.

Lacoste, Y. (2008) A Geografia - Isso serve, em primeiro lugar, para fazer a guerra. $14^{a}$ Ed. Campinas: Papirus.

Lawson, Tony (1997) Economics and Reality. Londres: Routledge.

Luhmann, N. (1997) Organización y Decisión: autopoiesis, acción y entendimiento comunicativo. [Queretaro (México): Universidad Iberoamericana de México/ Ediciones Anthropos.

Pimentel, Thiago D. (2012) "Espaço, Identidade e Poder: esboço de uma teoria morfogenética e morfostática para a sociologia das organizações". Tese de doutorado UFJF. Juiz de Fora.

Pimentel, Thiago D. (2014) "Realismo crítico nos estudos organizacionais: notas introdutórias sobre seus fundamentos filosóficos". Farol-Revista de Estudos Organizacionais e Sociedade, 1: 609-656.

Pimentel, Thiago D. (2015) "An ontology of organizational sociology and collective action. In 18th Annual Conference of the International Association for Critical Realism. Proceedings... Notre Dame University, South Bend, Indiana (USA).

Popper, Karl. (2010) “Textos Escolhidos / Karl Popper”. In Miller, David (Org.) Rio de Janeiro: Contraponto: Ed. PUC-Rio.

Popper, Karl (2011). A Lógica da Pesquisa Científica. São Paulo: Editora Cultrix.

Prado, Eleutério F. S. (2009) Economia, Complexidade e Dialética. São Paulo: Plêiade.

Rodriguez, Rodrigo S. (2015) "Racionalidade neoclássica: uma crítica além do positivismo". Revista Espacio Crítico, Bogotá, 22: 40-50.

Rosenberg, Alexander. (1980) "A skeptical history of microeconomic theory”. Theory And Decision, Virginia, 12: 79-93.

Searle, John. (2001) Rationality in Action. Cambridge: MIT Press.

Sent, Esther-Mirjam (2004) "Behavioral economics: how psychology made its (limited) way back into economics". History of Political Economy, 36(4): 735-760.

Simon, Herbert (1955) "A behavioral model of rational choice". The Quarterly Journal of Economics, 69 (1): 99-118.

Simon, Herbert. (1956) "Rational choice and the structure of the enviroment" Psychological Review, 63(2).

Sohn-Rethel, Alfred. (1978) Intellectual and Manual Labor: A Critique of Epistemology. The Macmillan Press.

Vandenberghe, Frédéric (2007) "Avatars of the Collective. A Realist Theory of Collective Subjectivities". Sociological Theory, 25 (4): 295-324.

Vandenberghe, Frédéric (2010). "Uma ontologia realista para a sociologia: morfogênese da sociedade e estruturação das subjetividades coletivas". In Vandenberghe, Frédéric. Teoria Social Realista: um diálogo franco-britânico. Belo Horizonte (MG): Editora UFMG/ Rio de Janeiro (RJ): IUPERJ, 183-256.

Weber, Max (1978) Economy and society: An outline of interpretive sociology. University of California Press. 